$$
\begin{aligned}
& \text { تأثير انحدار سطح التربة على أداء مصدر تتقيط خطي:(أ) نمط الابتلال }
\end{aligned}
$$

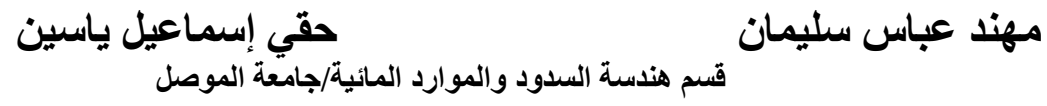

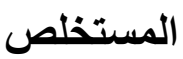

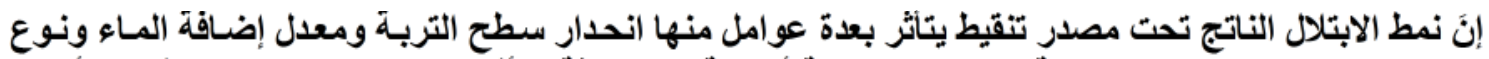

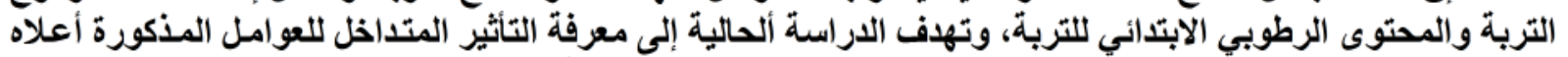

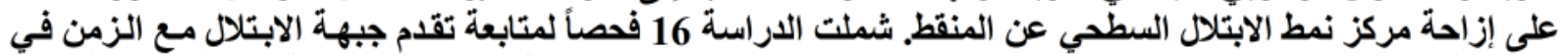

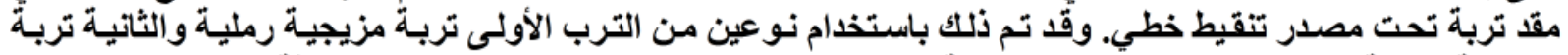

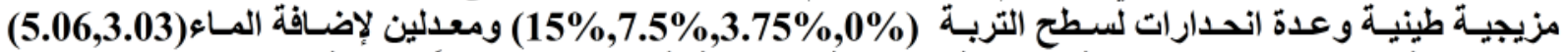

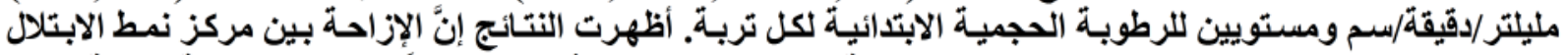

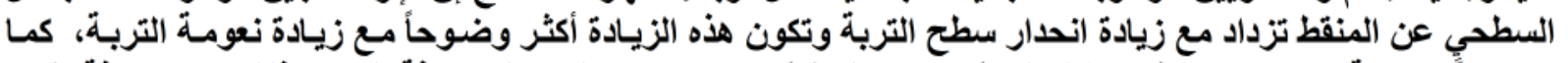

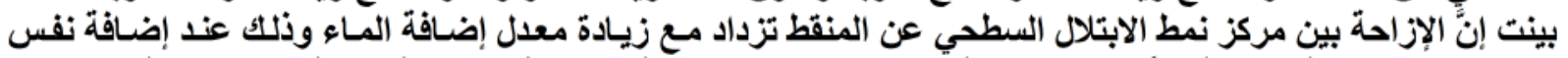

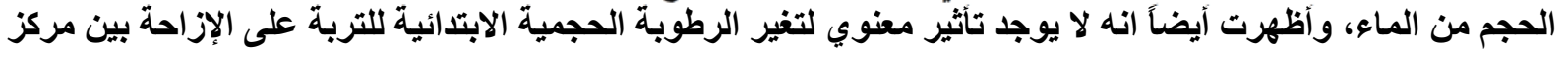

$$
\text { : الري بالتنقيط، }
$$

\title{
Effect Of Soil Surface Slope On The Performance Of Trickle Line Source:(A) Wetted Pattern
}

\begin{abstract}
The soil wetting pattern under the trickle source be affected by several factors, and these factors are the soil surface slope, water application rate, soil type, and the initial soil moisture content. The aim of the study is to find out the einterferences effects of the above factors on displacement of surface wetting pattern center from the trickler. The study included 16 test to monitor the advance of the wetting front with time in the soil profile under trickle line source. This was done by using sandy loam soil and clay loam soil, several soil surface slopes are applied $(0 \%, 3.75 \%, 7.5 \%, 15 \%)$ two water application rates $(3.03,5.06) \mathrm{ml} / \mathrm{min} / \mathrm{cm}$ and two levels of the initial soil moisture contentand for the two type of soil. The results showed that the displacement of surface wetting pattern center from the trickler increases with the increase of soil surface slope, and this increase is more clear with the increasing of the soil softness. Also it showed that the displacement of surface wetting pattern center from the trickler increases with the increase of water application rate at the same applied water volume. And also showed there is no significant effect of initial soil moisture on the displacement of surface wetting pattern center from the trickler for two study soils.
\end{abstract}

Key words: trickle irrigation, wetting pattern, soil surface slope.

$$
16-1-2014:
$$




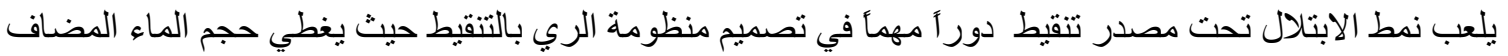

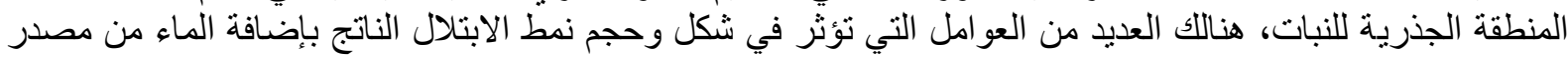

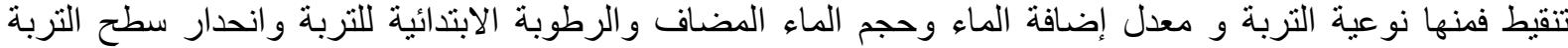

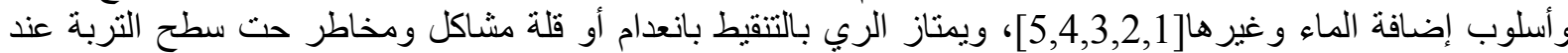

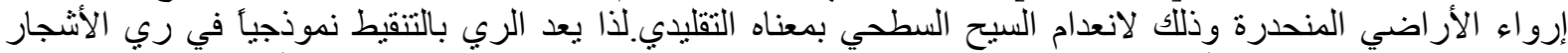

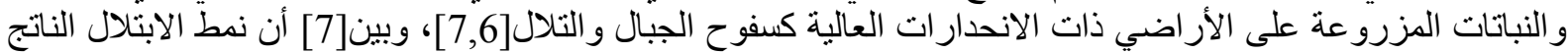

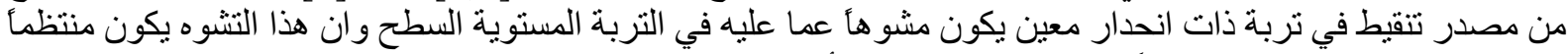

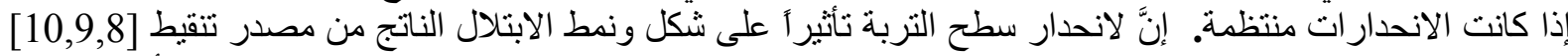

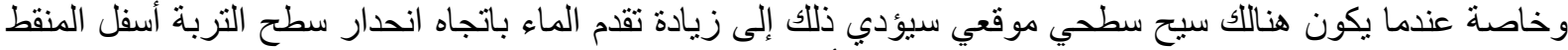

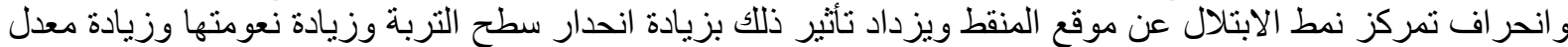

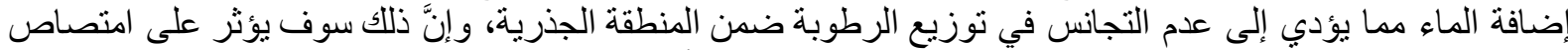

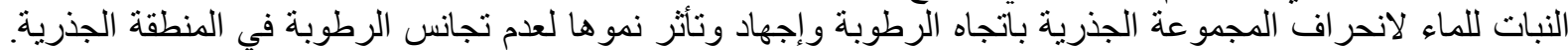

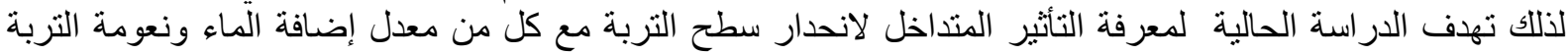
و الرطوبة الابتدائية للتربة على إز احة مركز نمط الابتلال الناتج من إضافة حجم معين من الماء عن مصدر التنقيط.

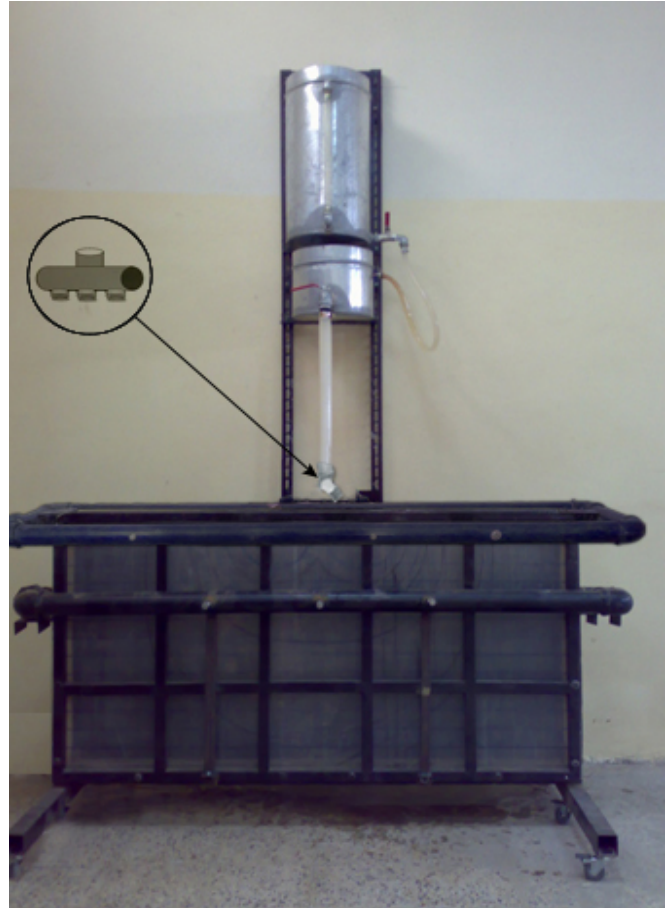

الثكل (1): حاوية التربة مع منظومة تجهيز الماء

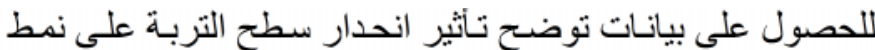

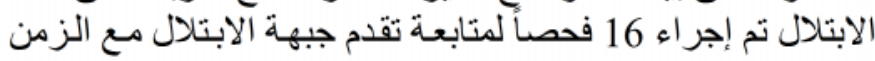

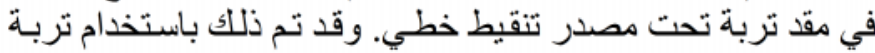

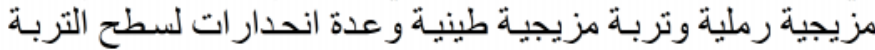

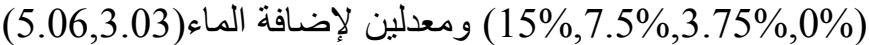

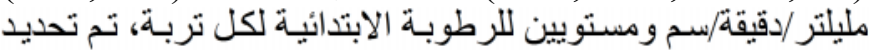

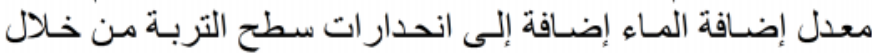

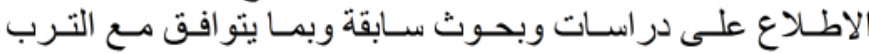

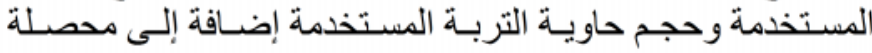

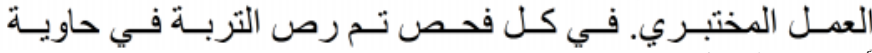
أبعادها(الطول140 وجه بلاستيكي شفاف وذللك لتهيئة مقد للتربة وبكثافة ظاهرية محددة

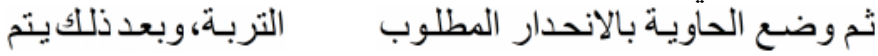

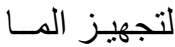
ليط

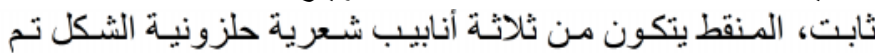

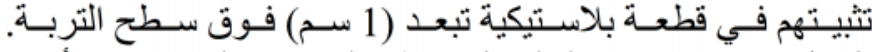
الثكل(1) يوضح حاوية التربة ومنظومـة تجهيز المـاء. وينتم تأثشير

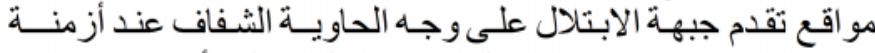

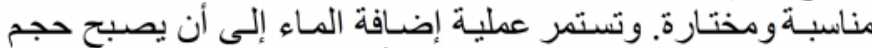

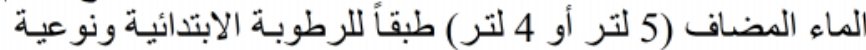

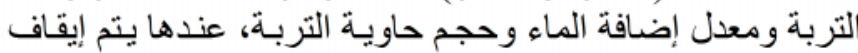

إضنافة الماء وتغطية سطح التربة بغطة التطاء

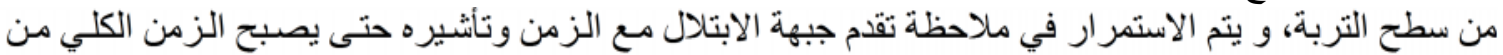

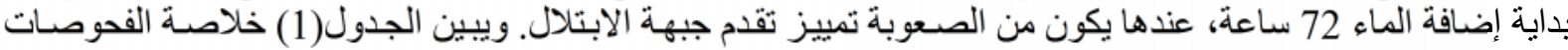


ياسين: تأثير اندار سطح التربة على أداء مصدر تنقيط خطي:(أ) نمط الابتلال

(1) : خلاصة الفحوصات المختبرية ولنو عين من الترب ولقيم مختلفة لانحدار ات سطح التربة.

\begin{tabular}{|c|c|c|c|c|}
\hline مليلتر /دقيقة/سم & $\%$ & وبة الابتدائية للتزبة & مليلتز & \\
\hline 3.03 & & \multirow{4}{*}{$5.7 \%$} & \multirow[b]{6}{*}{5000} & \multirow{8}{*}{ الرزيجية } \\
\hline 5.06 & $7.5 \%$ & & & \\
\hline 3.03 & \multirow[b]{2}{*}{$15 \%$} & & & \\
\hline 5.06 & & & & \\
\hline 3.03 & $7.5 \%$ & \multirow[b]{2}{*}{$14.3 \%$} & & \\
\hline 5.06 & $0 \%$ & & & \\
\hline 3.03 & $15 \%$ & \multirow[b]{2}{*}{$14.3 \%$} & \multirow[b]{2}{*}{4000} & \\
\hline 5.06 & $3.75 \%$ & & & \\
\hline \multirow{2}{*}{3.03} & $7.5 \%$ & \multirow[b]{2}{*}{$4.8 \%$} & \multirow{8}{*}{$\frac{4000}{5000}$} & \multirow{8}{*}{ الطزيجية } \\
\hline & $15 \%$ & & & \\
\hline \multirow{2}{*}{3.03} & $7.5 \%$ & \multirow[b]{2}{*}{$13.7 \%$} & & \\
\hline & $15 \%$ & & & \\
\hline \multirow{2}{*}{5.06} & $3.75 \%$ & \multirow[b]{2}{*}{$4.8 \%$} & & \\
\hline & $7.5 \%$ & & & \\
\hline 5.06 & $3.75 \%$ & $13.7 \%$ & & \\
\hline 5.06 & $0 \%$ & $4.8 \%$ & & \\
\hline
\end{tabular}

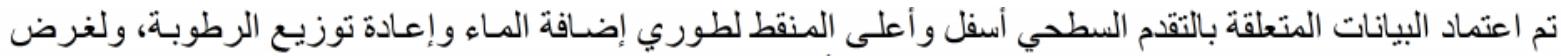

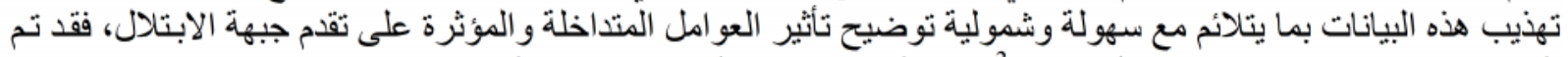

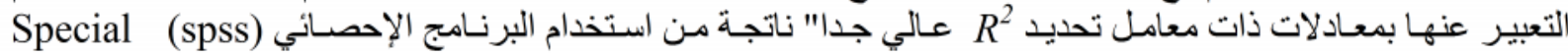
Program for Statistical System و واستخدام طريقة الانحدار اللاخطي، قيمة للتربة المزيجية الطينية وذلك لكل من التقدم السطحي أسفل المنقط

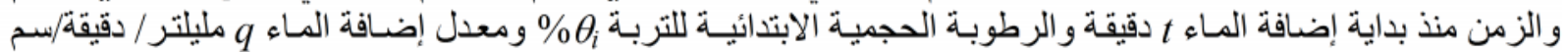

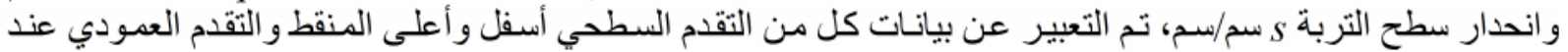
ولنو عين من الترب خلال طور إضافة الماء بالصيغة الآتية:

$\left(X_{d}, X_{u}\right)=A_{1}{ }^{*} t^{A 2} * \theta_{i}{ }^{A 3} * q^{A 4}+A_{5} * t^{A 6} * S^{A 7}$

(2) يبين قيم المعاملات لصيغة المعادلة (1) لإيجاد كل من بيانات التقدم السطحي أسفل و أعلى المنقط عند المنقط

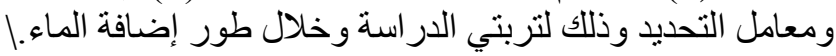

(2): قيم المعاملات لصيغة المعادلة(1) للتعبير عن بيانات التقدم السطحي أسفل وأعلى المنقط ومعامل التحديد

\begin{tabular}{|c|c|c|c|c|c|c|c|c|c|}
\hline$R^{2}$ & $A_{7}$ & $A_{6}$ & $A_{5}$ & $A_{4}$ & $A_{3}$ & $A_{2}$ & $A_{1}$ & $ت$ \\
\hline 0.989 & 0.35 & 0.4708 & 4.6082 & 2.0574 & 0.3197 & 0.4708 & $\mathbf{0 . 2 8 8 6}$ & $X_{d}$ & \\
\hline 0.9777 & 0.35 & $\mathbf{0 . 4 5 3 1}$ & -3.395 & $\mathbf{0 . 1 2 3 7}$ & $\mathbf{0 . 1 2 2 7}$ & $\mathbf{0 . 4 5 3 1}$ & $\mathbf{4 . 7 3 2 1}$ & $X_{u}$ & \\
\hline 0.991 & 0.35 & $\mathbf{0 . 6 2 9 8}$ & $\mathbf{2 . 3 3 6 8}$ & $\mathbf{1 . 2 4 9 3}$ & $\mathbf{0 . 1 3 5 6}$ & $\mathbf{0 . 6 2 9 8}$ & $\mathbf{0 . 5 0 5 8}$ & $X_{d}$ & \\
\hline 0.983 & 0.35 & $\mathbf{0 . 4 8 3 7}$ & $-\mathbf{3 . 0 7 5}$ & $\mathbf{0 . 2 5 5 5}$ & $\mathbf{0 . 0 2 0 6}$ & $\mathbf{0 . 4 8 3 7}$ & $\mathbf{3 . 3 7 5}$ & $X_{u}$ & \\
\hline
\end{tabular}




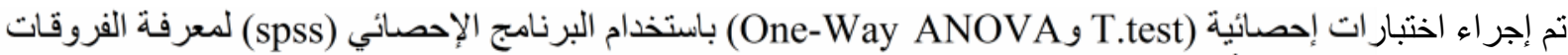

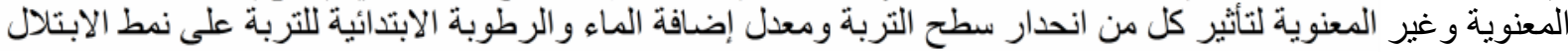

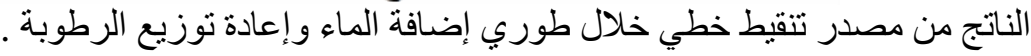

الإزاحة بين مركز نمط الابتلال السطحي عن المنقط (d): مركز نمط الابتلال السطحي هو معدل كل من التقدم

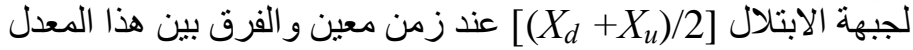

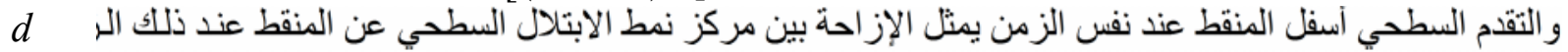
(2)، و الذي يمكن التعبير عنه بالاتي:
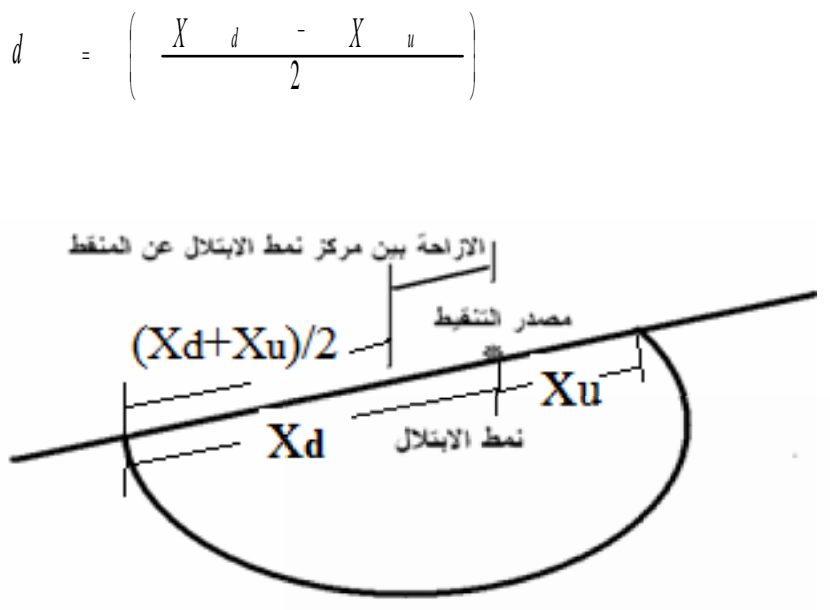

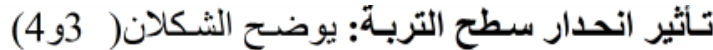

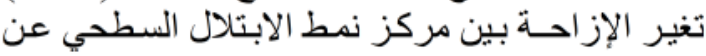

$\% 15, \% 7.5, \% 3.75$

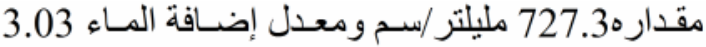
مليلتر /دقيقة/سم ومستويين للرطوبـة الابتدائية 5.7 \%

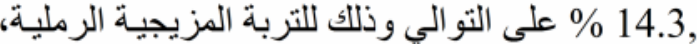

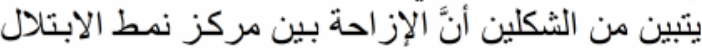

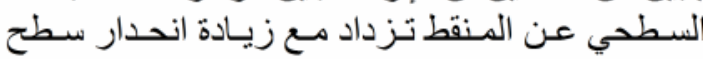

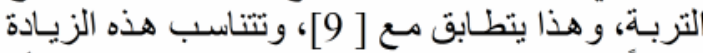

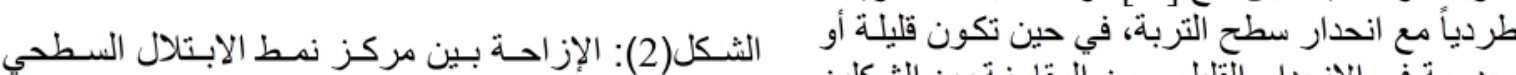

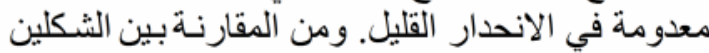

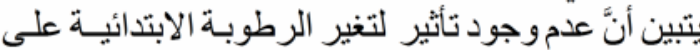

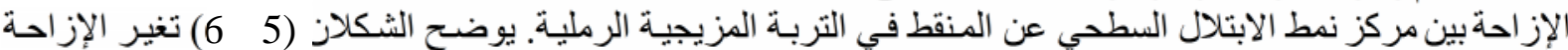

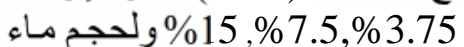

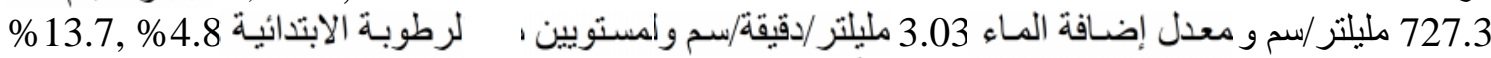
بين مركز نمط الابتلال

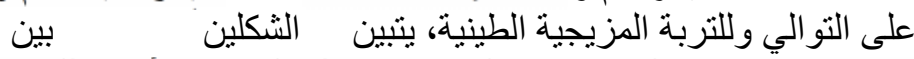

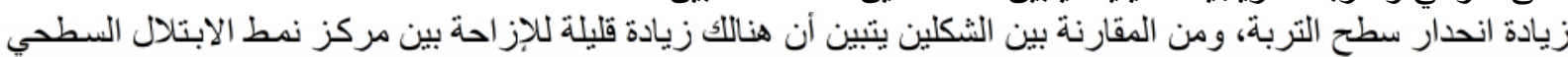

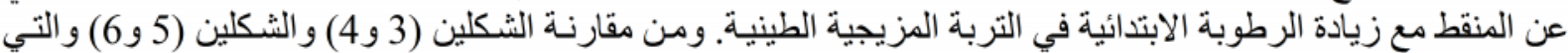

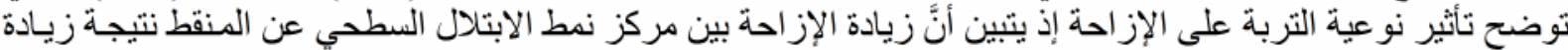

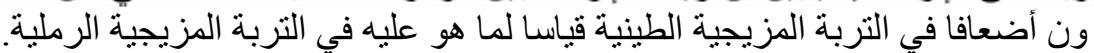

تأثير معدل إضافة الماء: يوضـح الثكلان (878) تغير الإزاحة بين مركز نمط الابتلال السطحي عن المنقط مـع الزمن

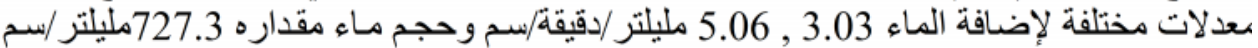

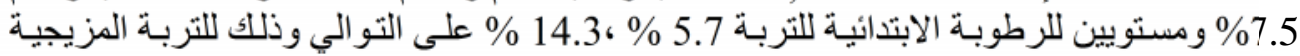

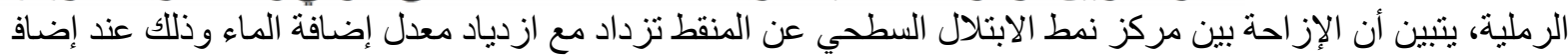

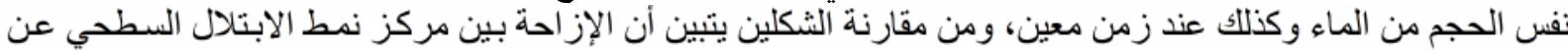

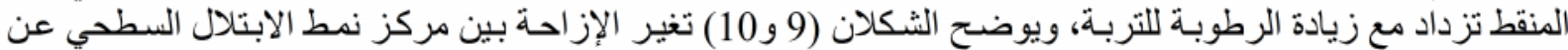

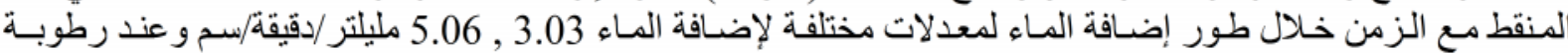
727.3 


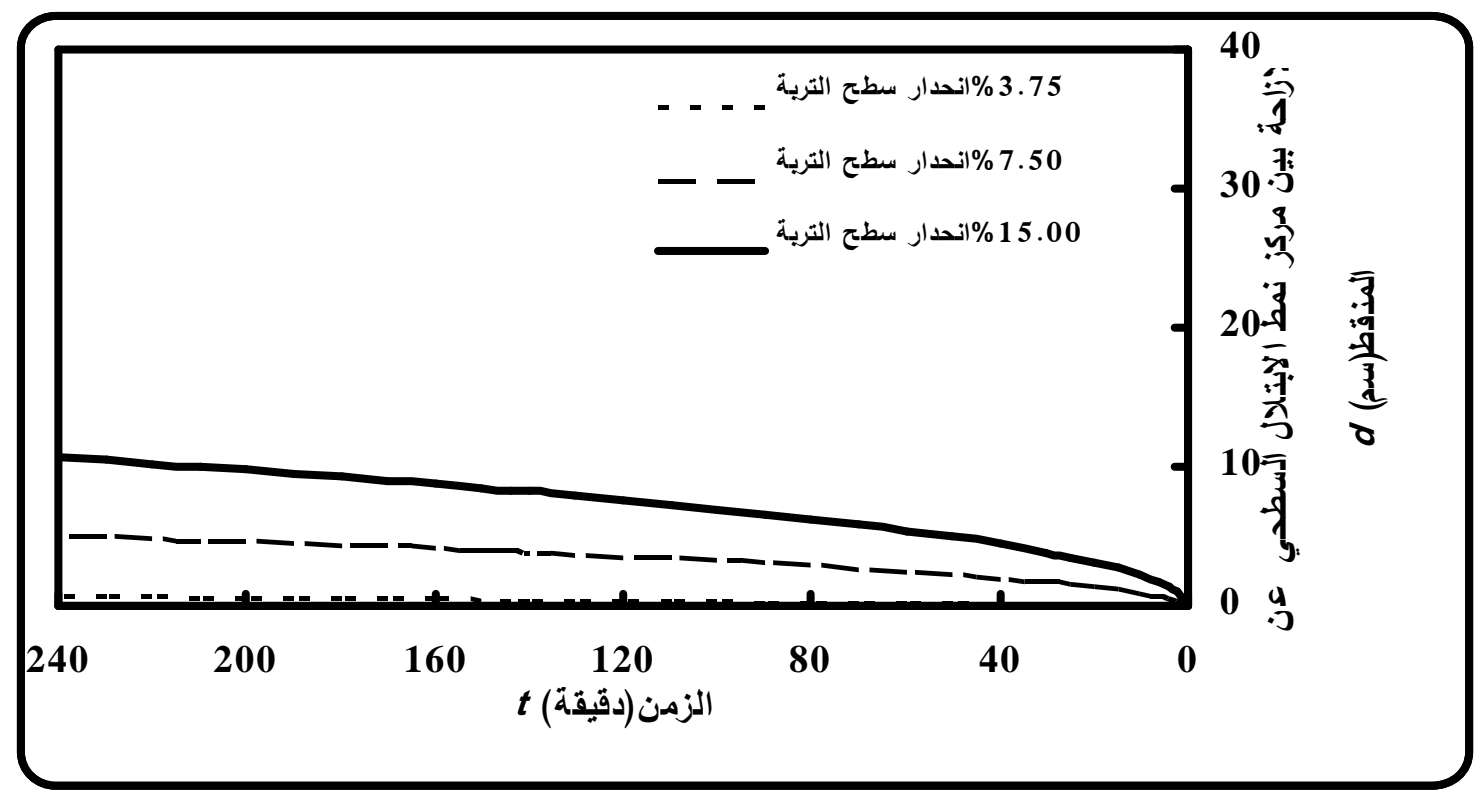

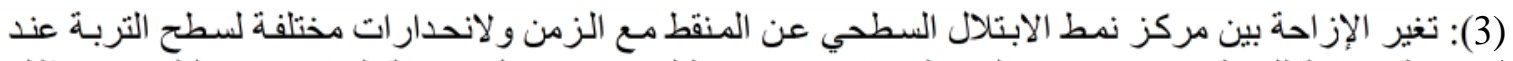

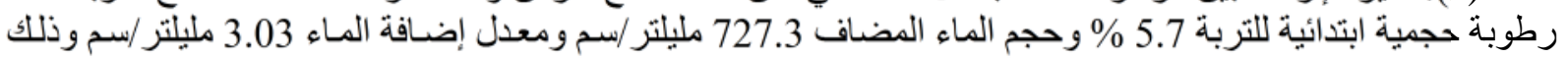
للتربة المزيجية الرملية.

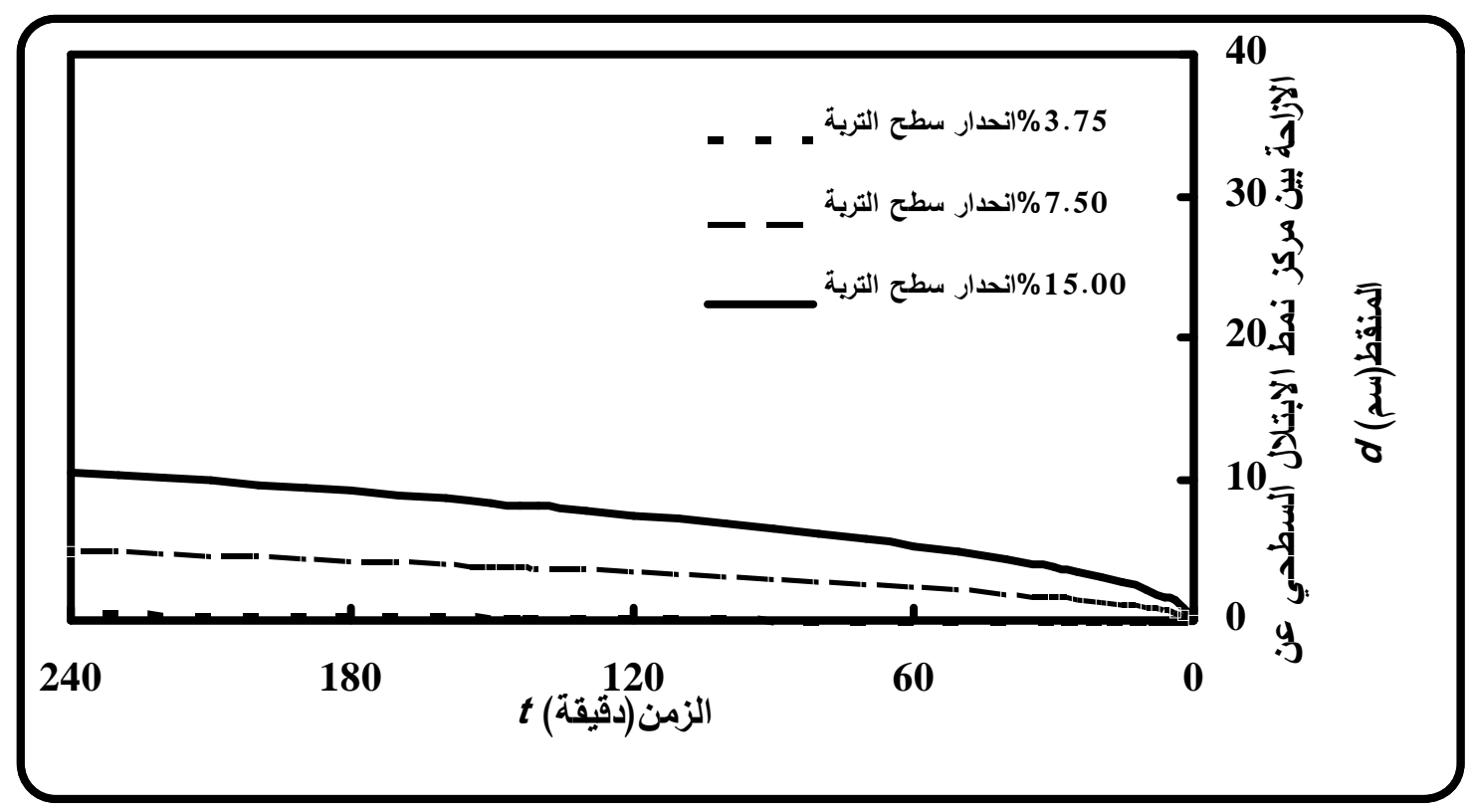

الثكل(4): تغير الإزاحة بين مركز نمط الابتلال السطحي عن المنقط مع الزمن و لانحدار ات مختلفة لسطح التربـة عند النداء

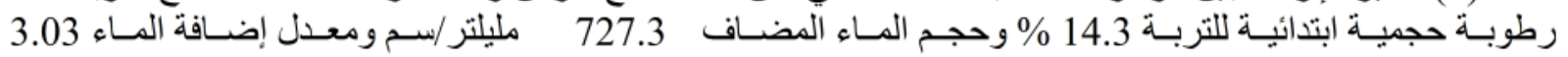
مليلتر/دقيقة/سم وذلك للتربة المزيجية الرملية. 
No. 5

Dec. 2014

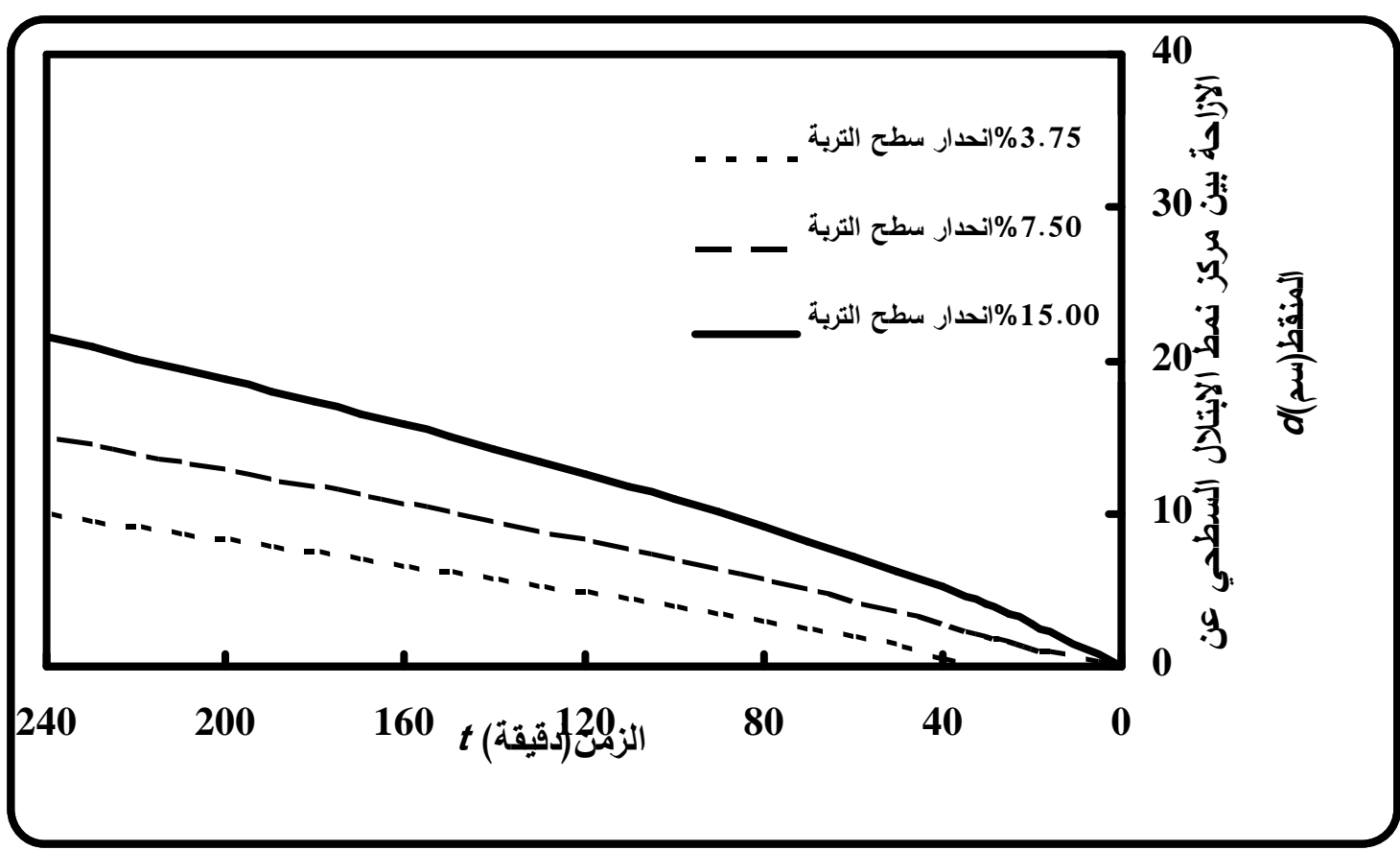

الثكل(5): تغير الإزاحة بين مركز نمط الابتلال السطحي عن المنقط مـع الزمن و لانحدار ات مختلفة لسطح التربـة عند

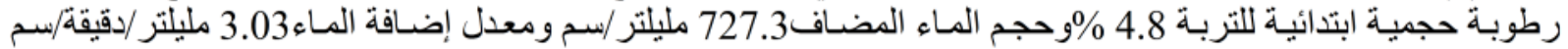
وذللك للتربة المزيجية الطينية.

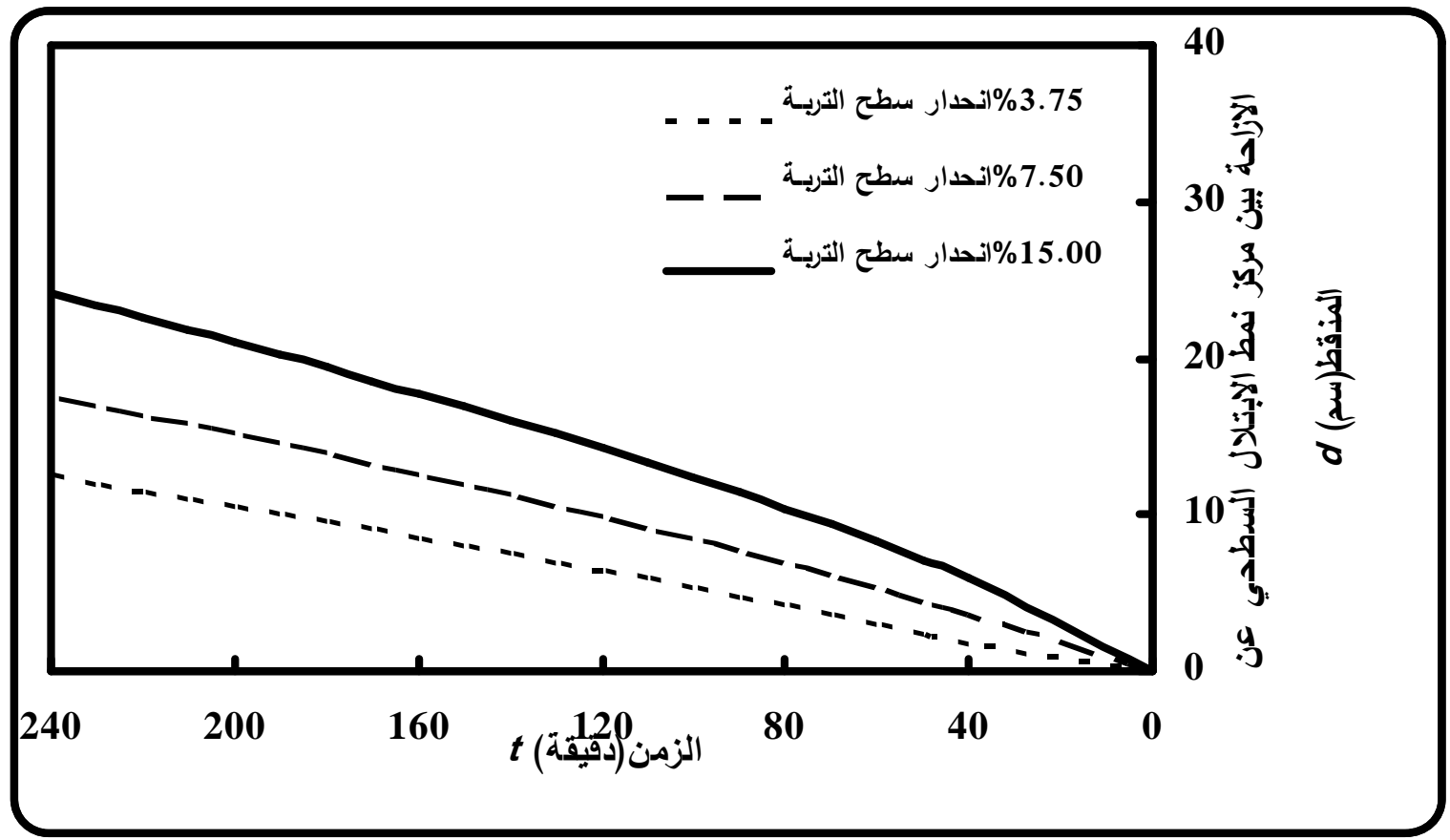

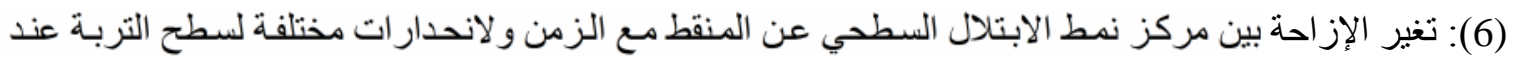

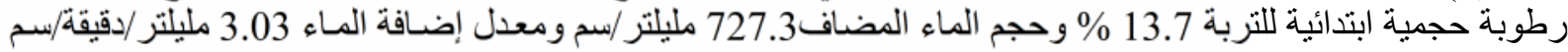
وذللك للتربة المزيجية الطينية. 
ياسين: تأثير انحدار سطح التربة على أداء مصدر تنقيط خطي:(أ) نمط الابتلال

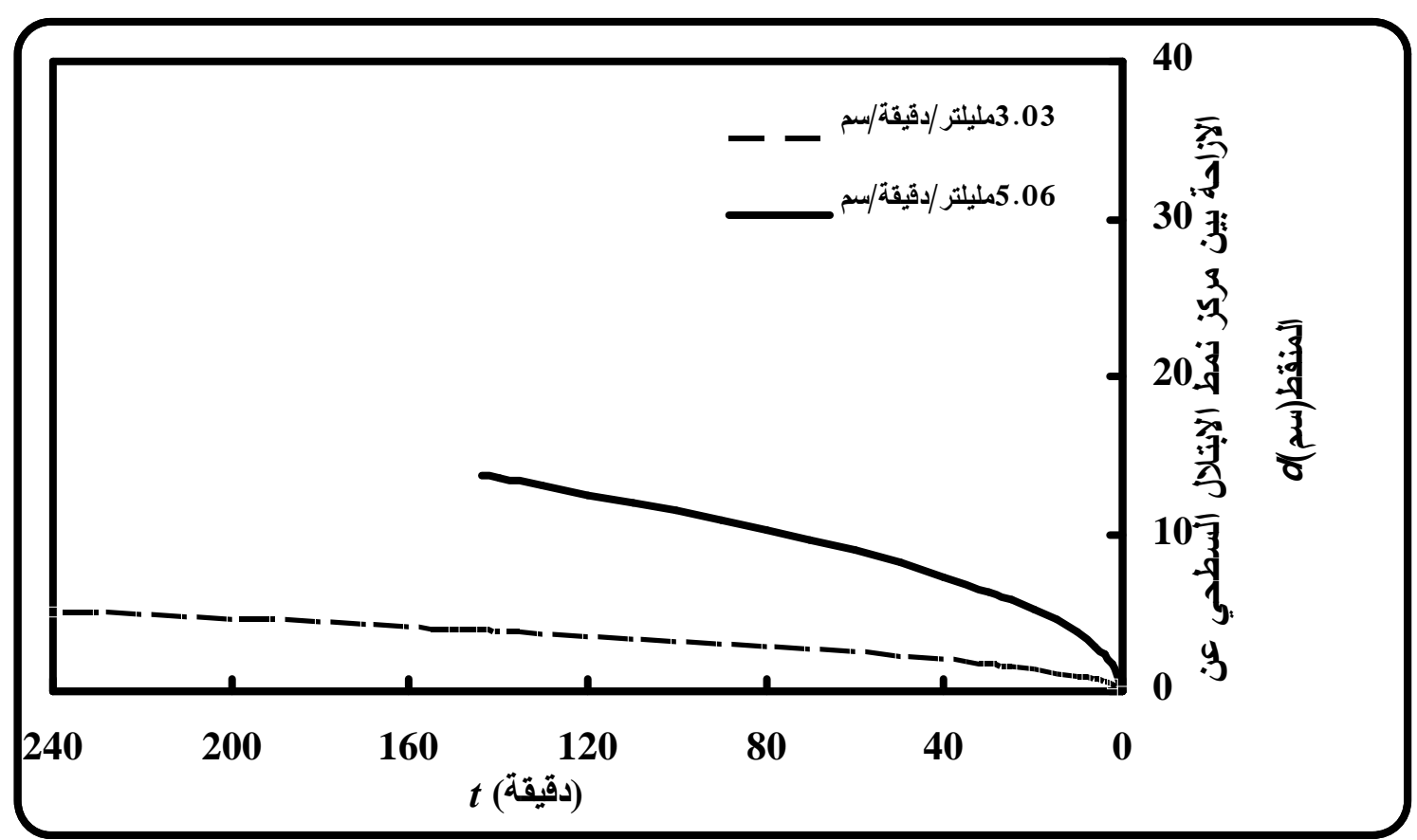

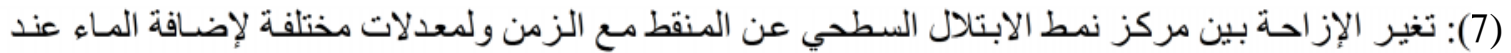

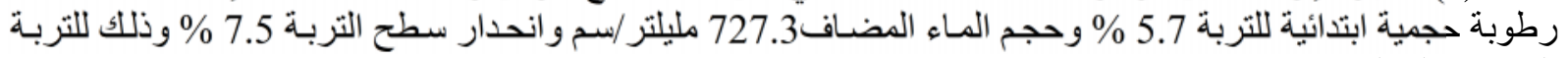
المزيجية الرملية.

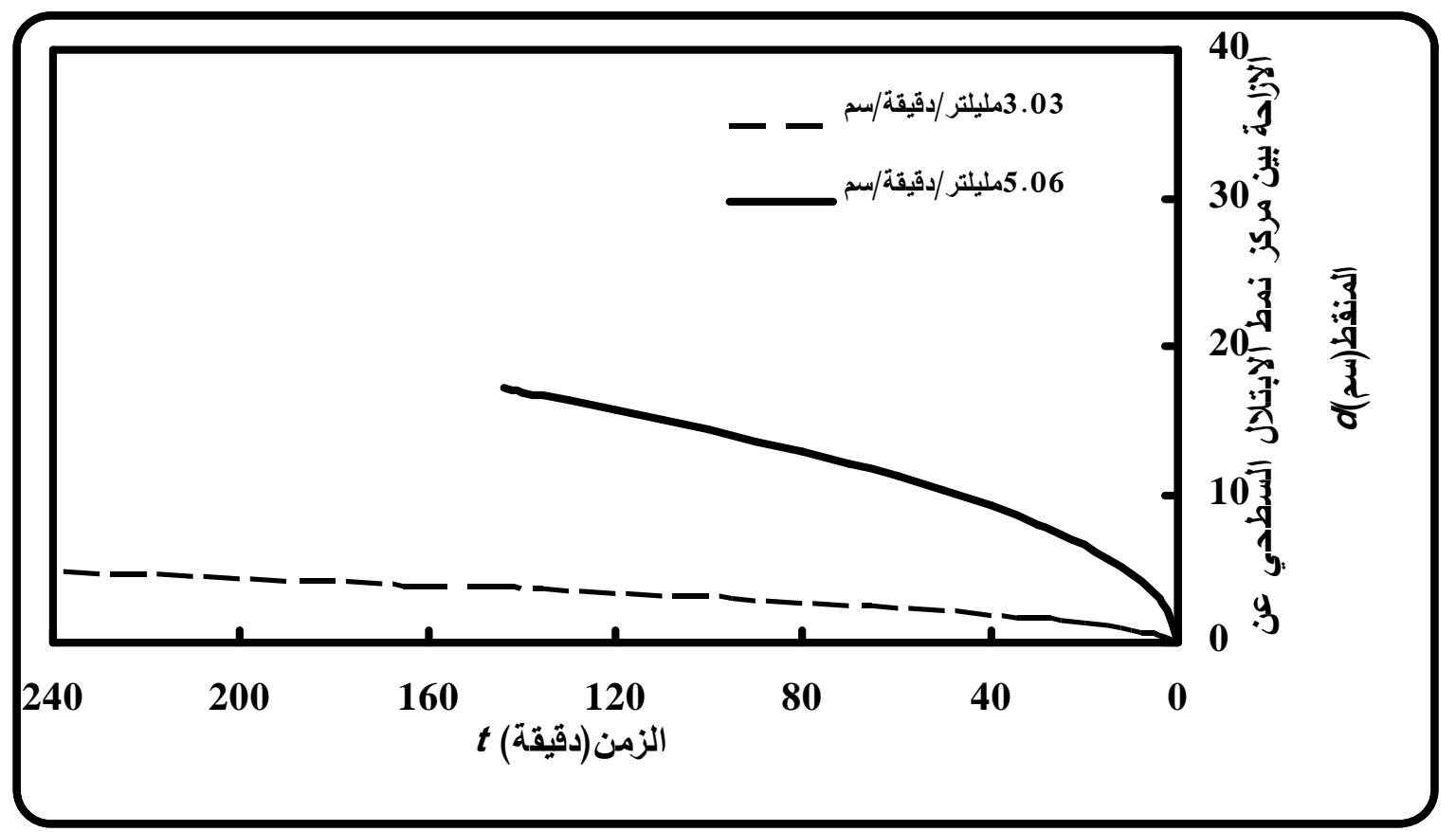

(8): تغير الإز احة بين مركز نمط الابتلال السطحي عن المنقط مـع الزمن ولمعدلات مختلفة لإضـافة المـاء عند 727.3 مليلتر/سم و انحدار سطح الزمن

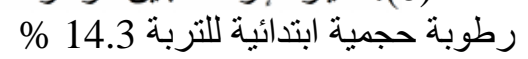
المزيجية الرملية. 


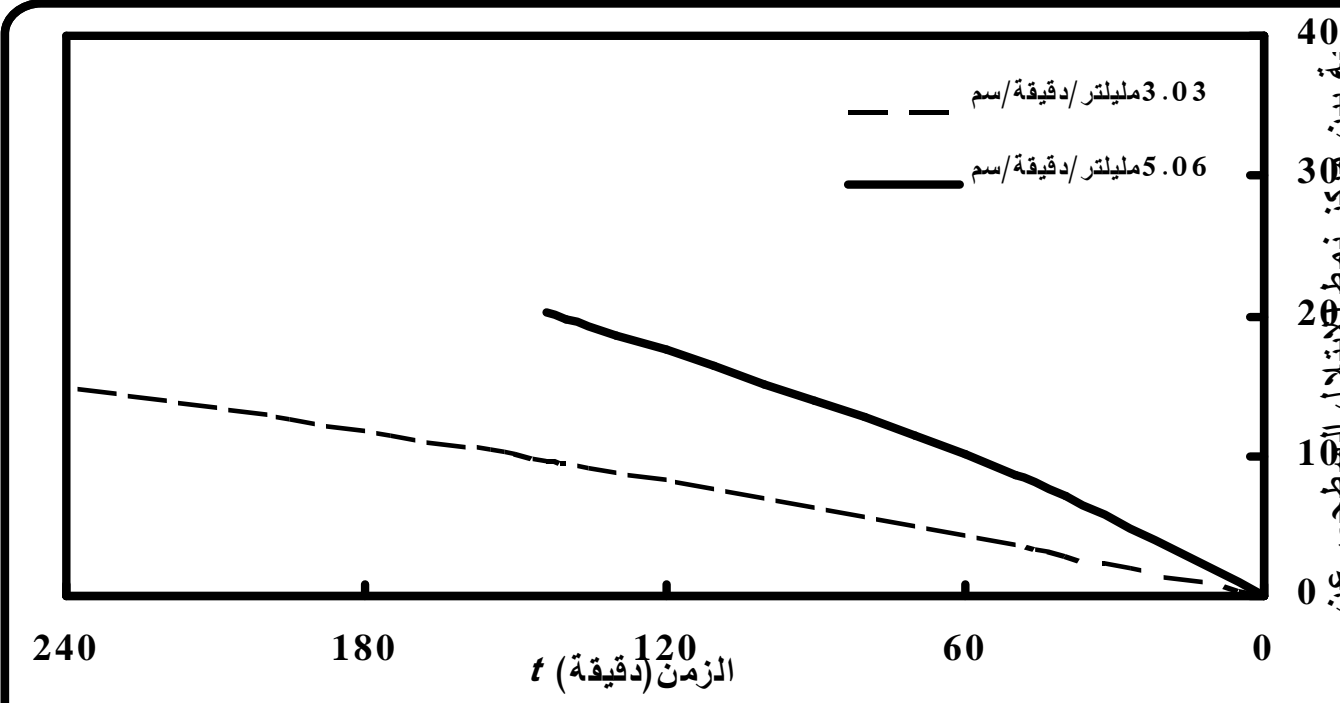

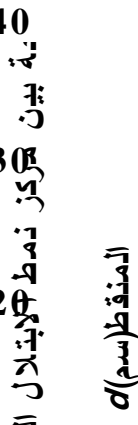

$1 \overline{\overline{0}}$

$\frac{\overline{7}}{\frac{7}{3}}$

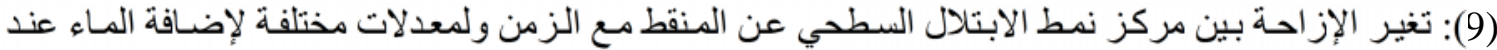

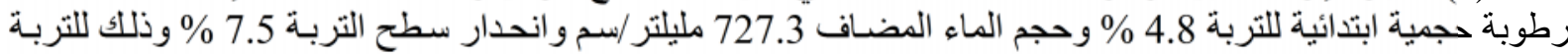
المزيجية الطينية البنة

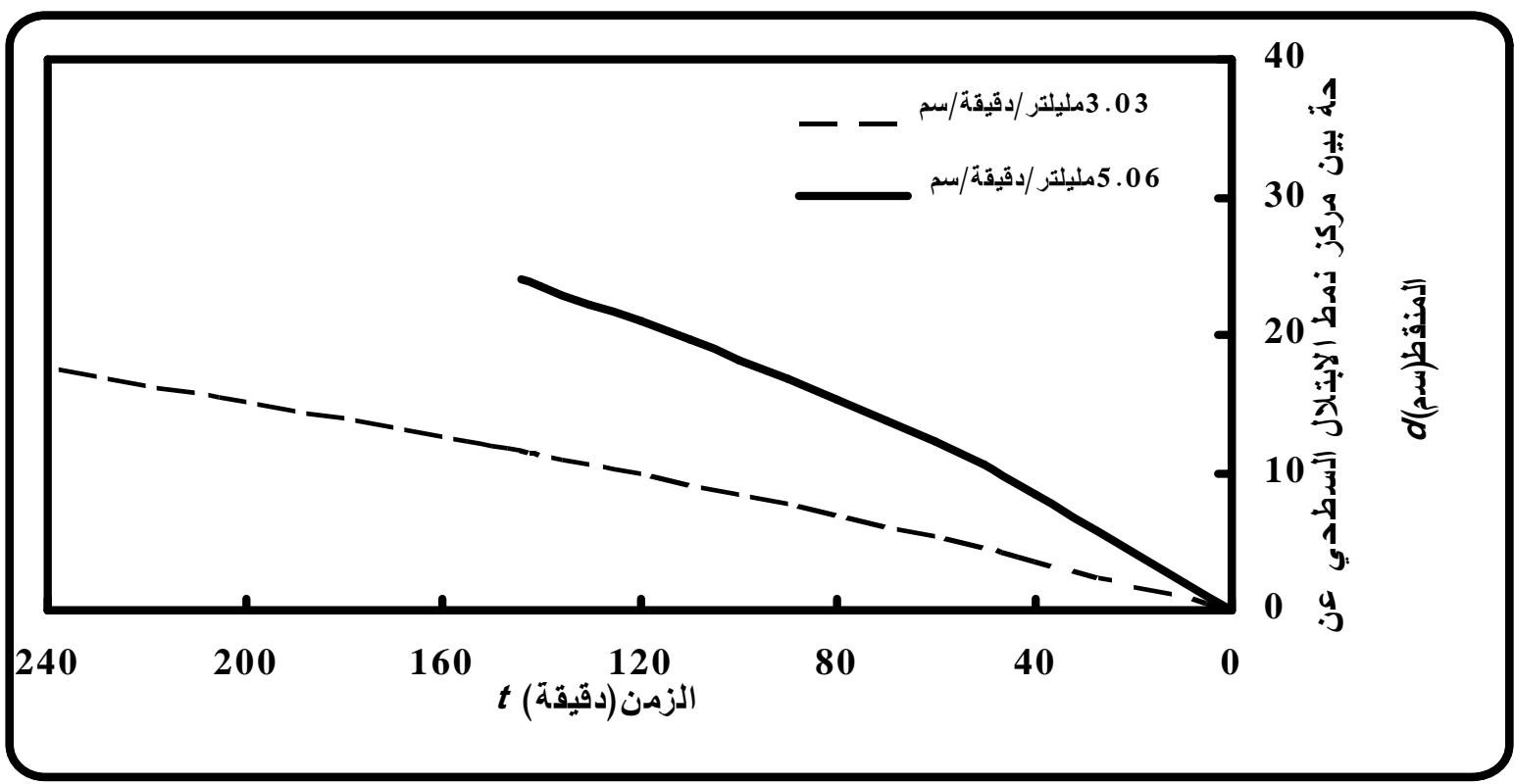

(10): تغير الإز احة بين مركز نمط الابتلال السطحي عن المنقط مـع الزمن ولمعدلات مختلفة لإضـافة المـاء عند رطوبة حجمية ابتدائية للتربة 13.7 \% و وحجم الماء المضاف 727.3 مليلتز /سم و انحدار سطح التربـة 7.5 \% وذللك للتربـة المزيجية الطينية.

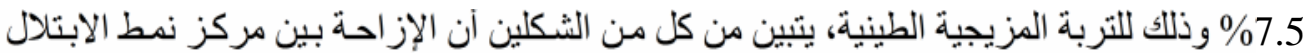

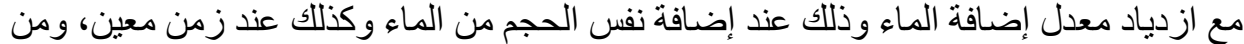

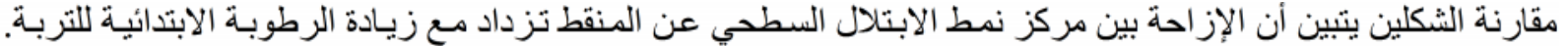

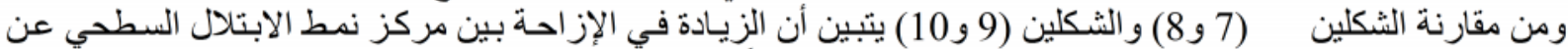

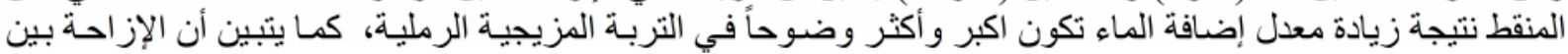
مركز نمط الابتلال السطحي عن المنقط في التربة المزيجية الطينية تكون اكبر مما هو الكئ عليه في التربة المزيجية الرملية. 


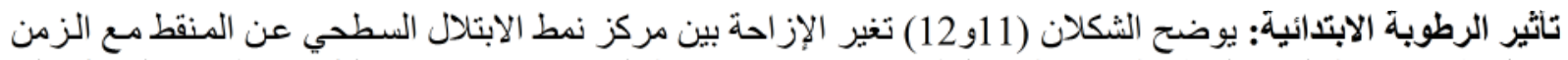

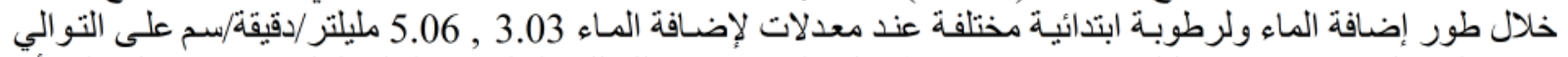

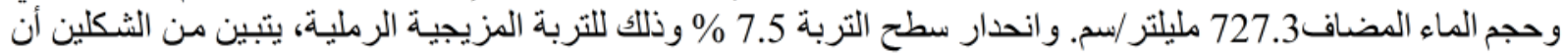

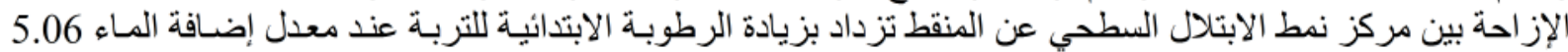

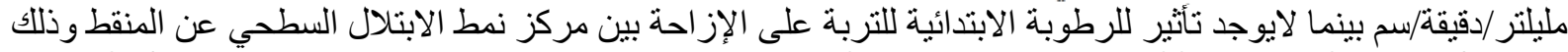

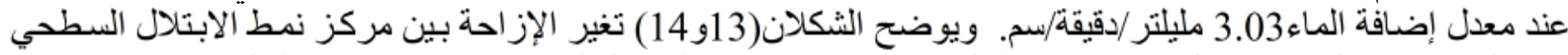

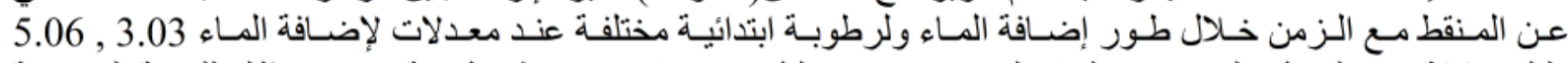
مليلتر/دقيقة/سم على التو الي وحجم المـاء المضاف

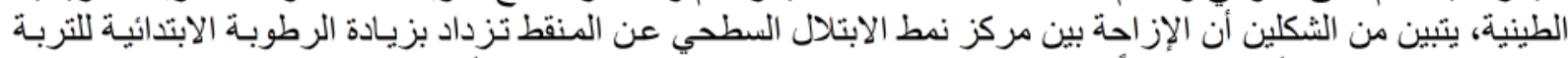

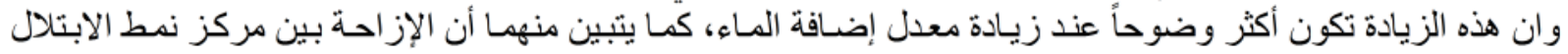

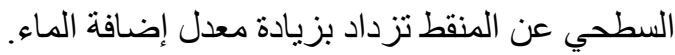

تأثير الارتثـاح التراكمي: يوضح الجدول (3) تأثثر الارتنشاح التر اكمي على الإزاحة بين مركز نمط الابتلال السطحي عن

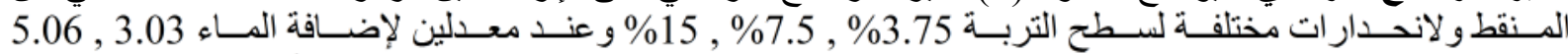

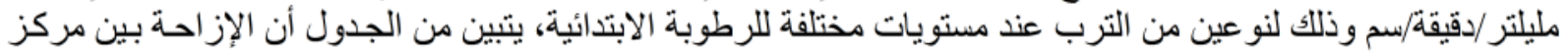

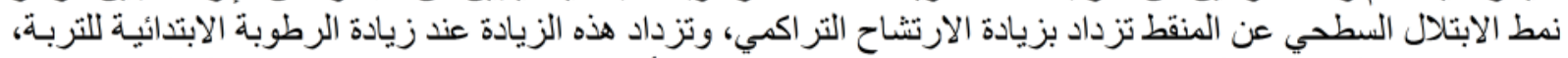

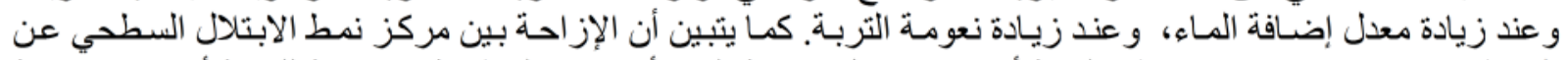

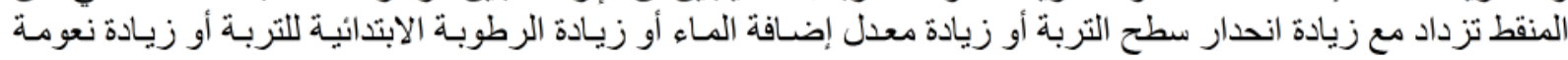

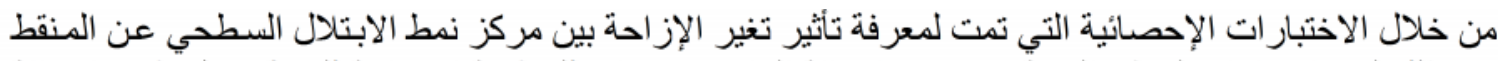

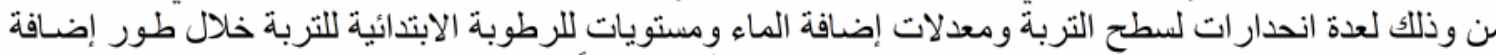

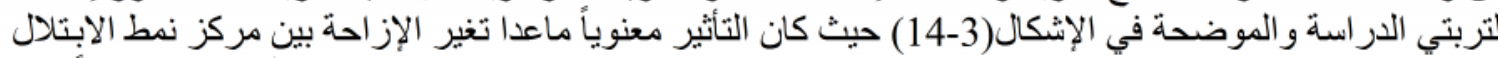
(14-11) حيث كان التأثير غير معنوياً.

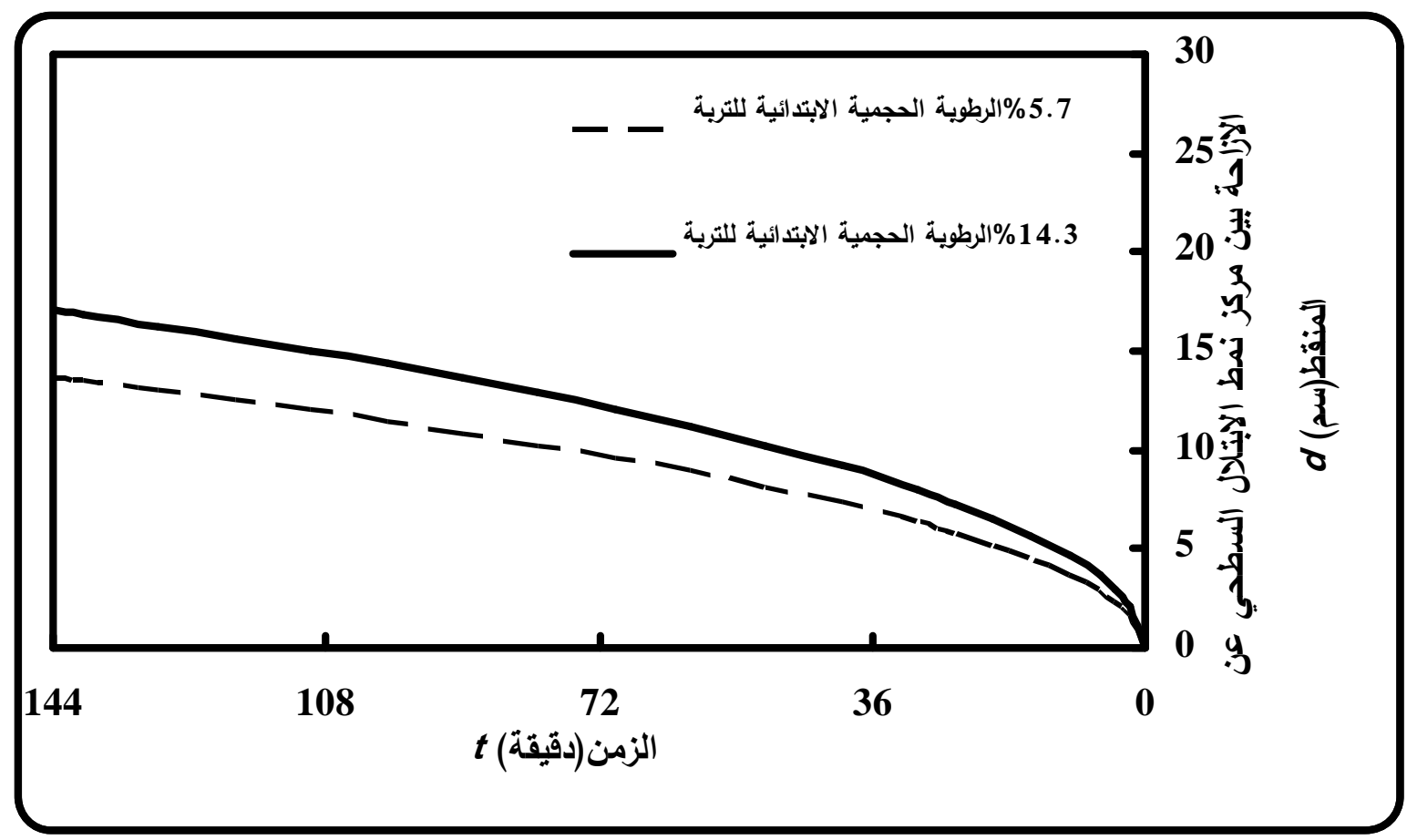

(11): تغير الإز احة بين مركز نمط الابتلال السطحي عن المنقط مـع الزمن ولرطوبـة ابتدائية مختلفة عند معدل

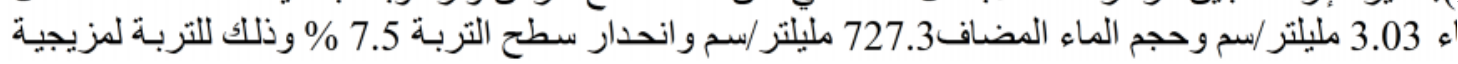


No. 5

Dec. 2014

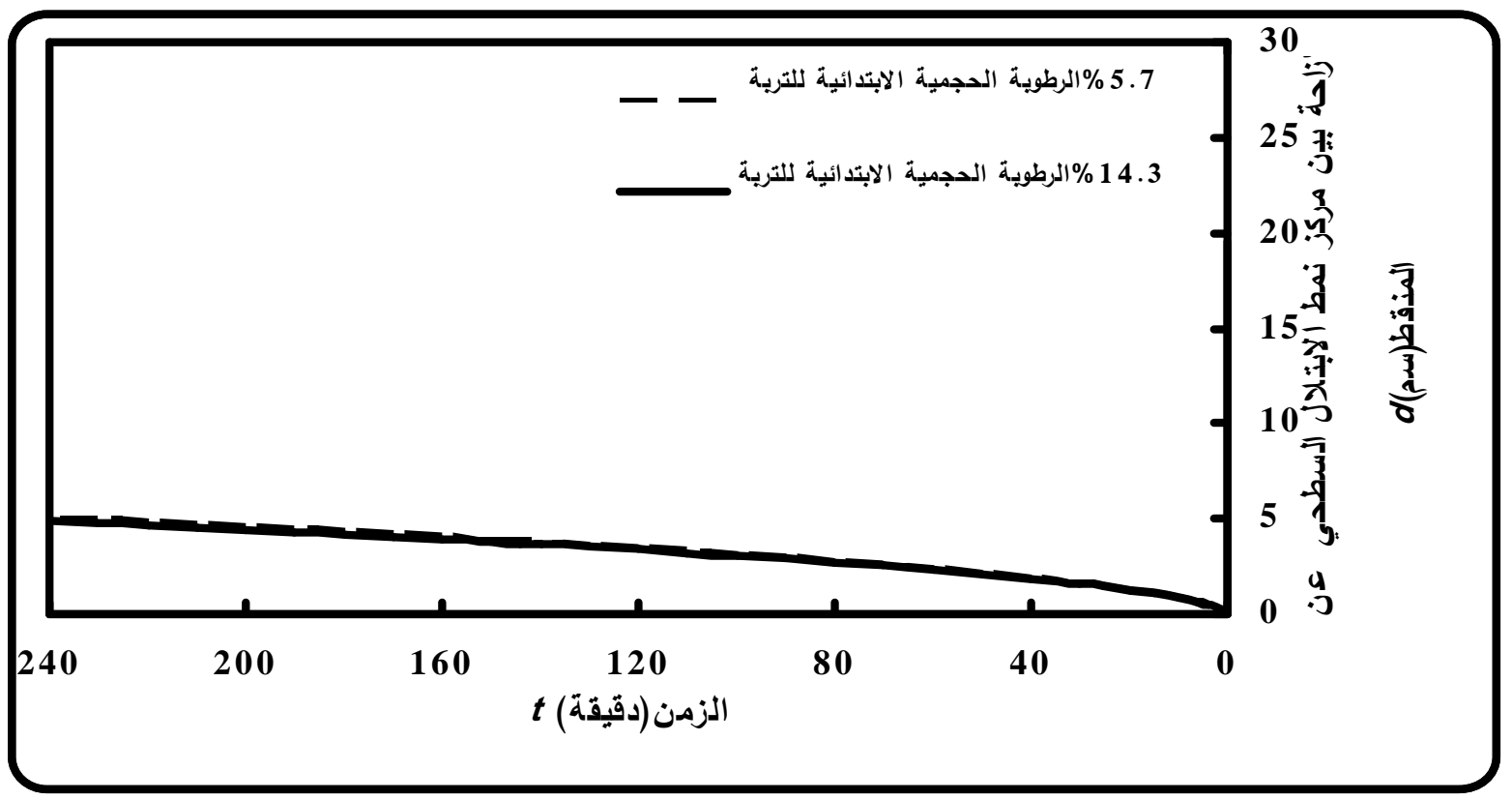

(12): تغير الإزاحة بين مركز نمط الابتلال السطحي عن المنقط مـع الزمن ولرطوبـة ابتدائية مختلفة عند معدل

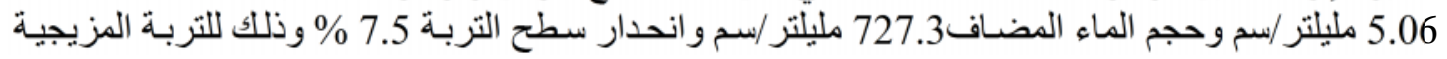

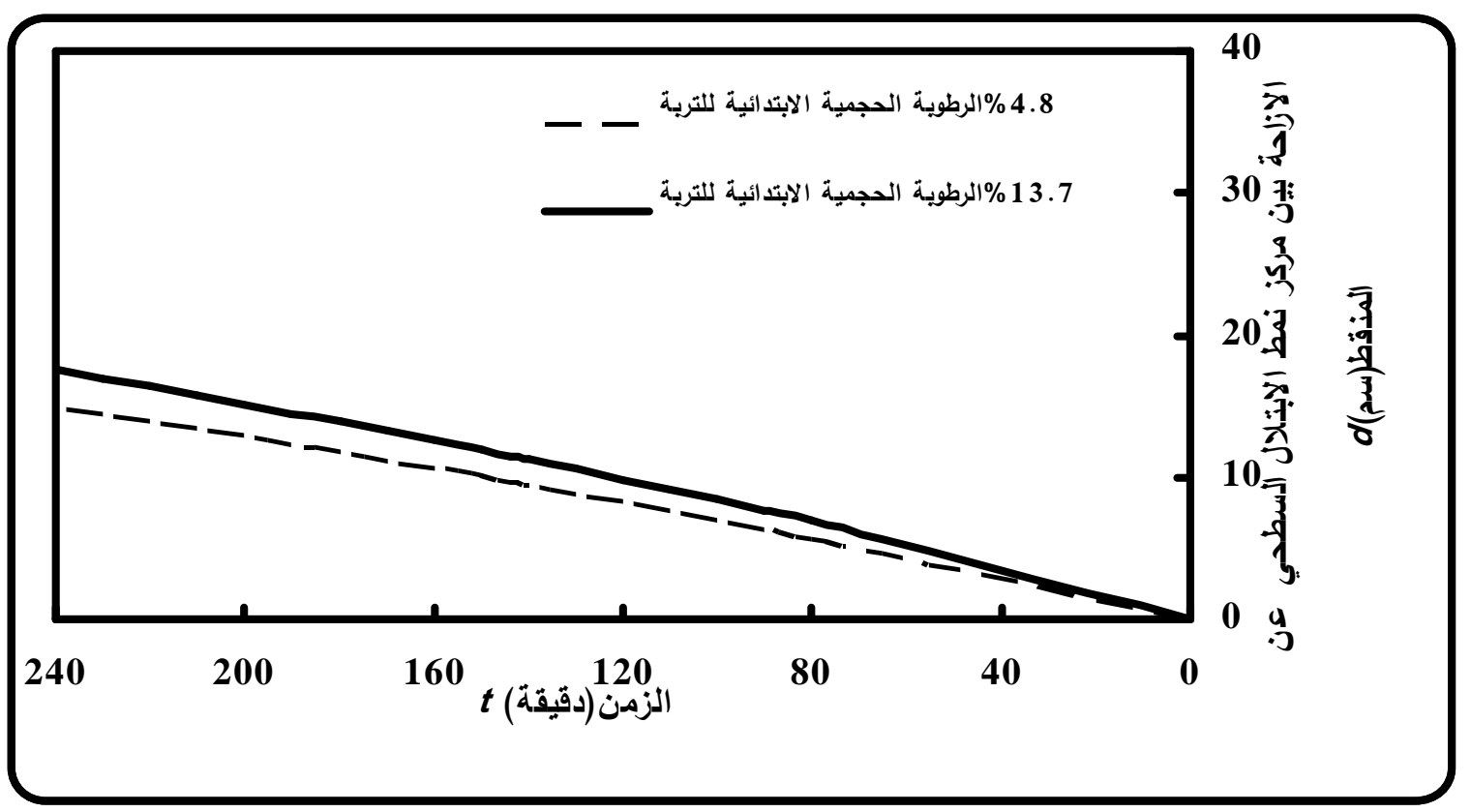

(13): تغير الإز احة بين مركز نمط الابتلال السطحي عن المنقط مع الزمن ولرطوبـة ابتدائية مختلفة عند معدل

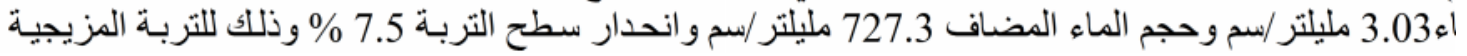


ياسين: تأثير انحدار سطح التربة على أداء مصدر تنقيط خطي:(أ) نمط الابتلال

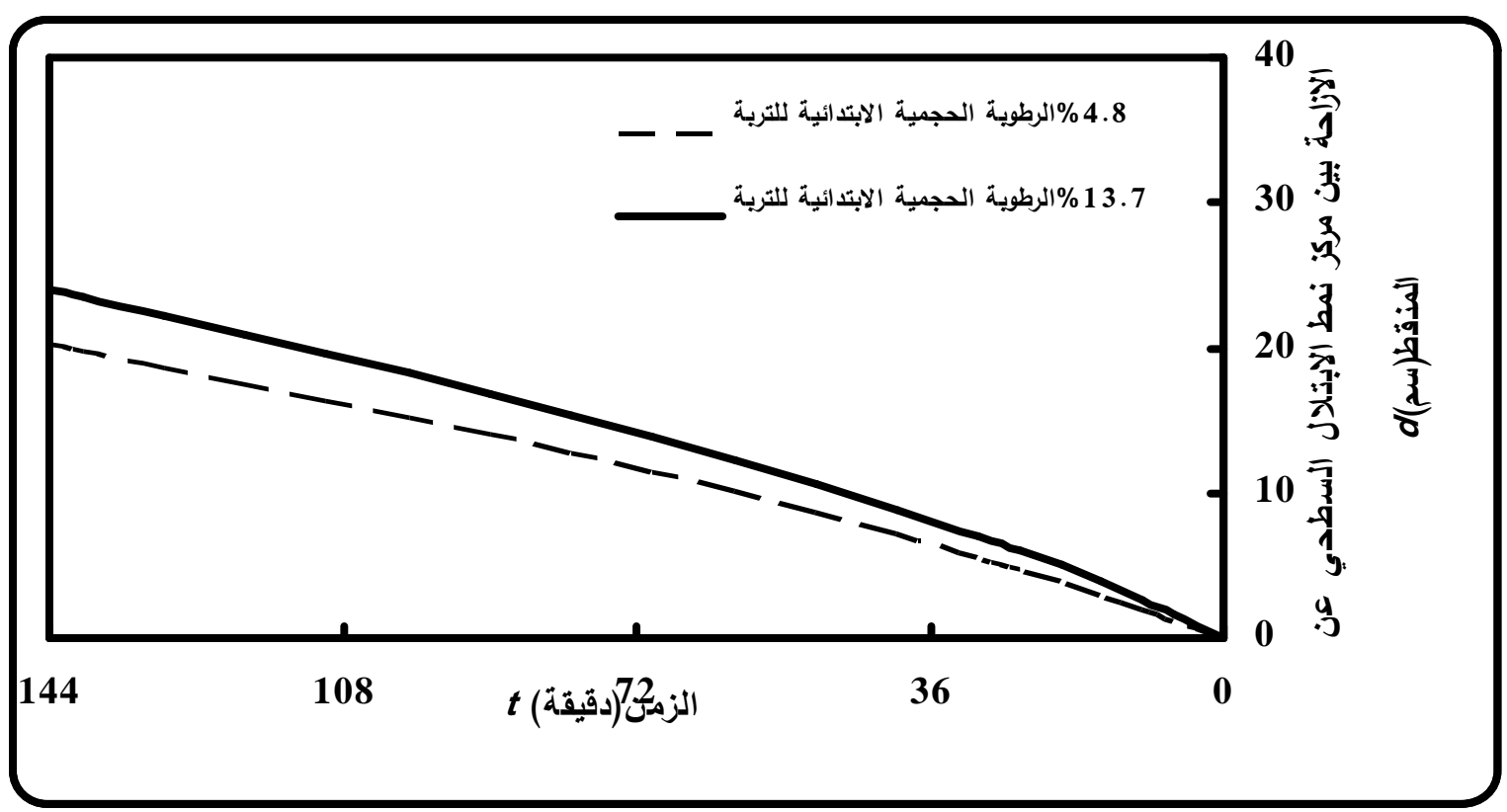

(14): تغير الإزاحة بين مركز نمط الابتلال السطحي عن المنقط مـع الزمن ولرطوبـة ابتدائية مختلفة عند معدل

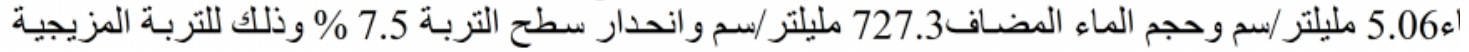

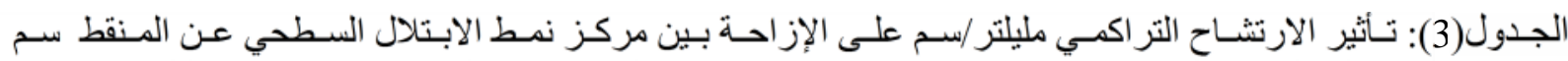

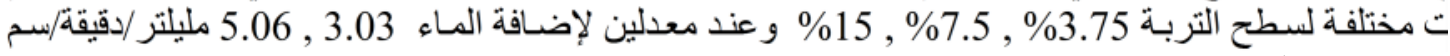
يات رطوبة ابتدائية .

\begin{tabular}{|c|c|c|c|c|c|c|c|c|}
\hline \multicolumn{3}{|c|}{ 5.06مليلتر/دقيقة/سد } & \multicolumn{3}{|c|}{ 3.03مليلتر/دقيقة/سم } & \multirow{3}{*}{ مليلتر/سم } & \multirow{3}{*}{ ابتدائية } & \\
\hline \multicolumn{2}{|c|}{$\%$} & & & & & & & \\
\hline$\% 15$ & $\% 7.50$ & $\% 3.75$ & $\% 15$ & $\% 7.50$ & $\% 3.75$ & & & \\
\hline 11 & 8.1 & 6 & 6.3 & 2.9 & 0.2 & 250 & \multirow{4}{*}{$\% 5.7$} & \multirow{4}{*}{ رزيجية } \\
\hline 15 & 11 & 8.5 & 8.9 & 4.2 & 0.5 & 500 & & \\
\hline 18 & 14 & 10 & 11 & 5.2 & 0.7 & 750 & & \\
\hline 21 & 16 & 12 & 13 & 6 & 0.9 & 1000 & & \\
\hline 11 & 8.6 & 6.5 & 9.4 & 5.8 & 3.1 & 250 & \multirow{4}{*}{$\% 4.8$} & \multirow{4}{*}{ طزيجية } \\
\hline 19 & 15 & 12 & 16 & 11 & 6.8 & 500 & & \\
\hline 26 & 21 & 17 & 22 & 15 & 10 & 750 & & \\
\hline 32 & 26 & 21 & 27 & 19 & 13 & 1000 & & \\
\hline 13 & 10 & 8 & 6.2 & 2.8 & 0.1 & 250 & \multirow{4}{*}{$\% 14.3$} & \multirow{4}{*}{ رزيجية } \\
\hline 18 & 14 & 11 & 8.7 & 4 & 0.3 & 500 & & \\
\hline 22 & 17 & 14 & 11 & 5 & 0.5 & 750 & & \\
\hline 25 & 20 & 16 & 12 & 5.8 & 0.7 & 1000 & & \\
\hline 13 & 11 & 8.4 & 11 & 7.1 & 4.3 & 250 & \multirow{4}{*}{$\% 13.7$} & \multirow{4}{*}{ طزيجية } \\
\hline 22 & 18 & 15 & 18 & 13 & 8.8 & 500 & & \\
\hline 29 & 25 & 21 & 25 & 18 & 13 & 750 & & \\
\hline 36 & 31 & 26 & 30 & 23 & 17 & 1000 & & \\
\hline
\end{tabular}


الإزاحة بين مركز نمط الابتلال السطحي عن المنقط خلال طور إعادة توزيع الرطوبة (d)

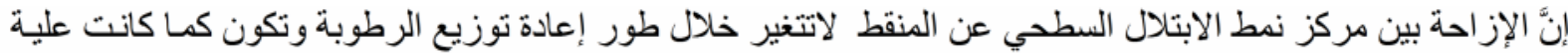

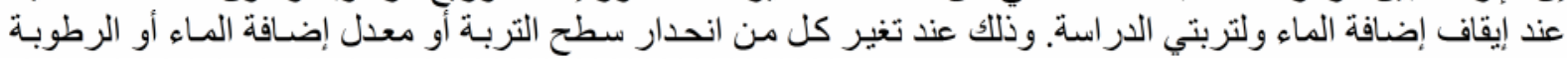
الابتدائية للتربة.

1. الإز احة بين مركز نمط الابتلال السطحي عن المنقط تزداد مع زيادة انحدار سطح التربـة وتكون هذه الزيادة أكثر

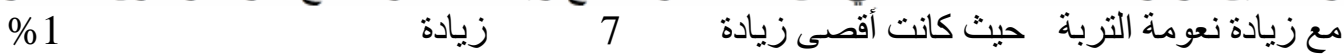
1000مليلتر /سم.

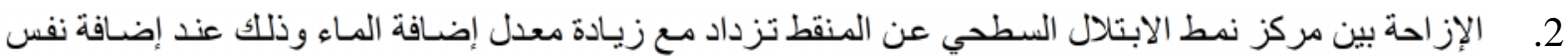

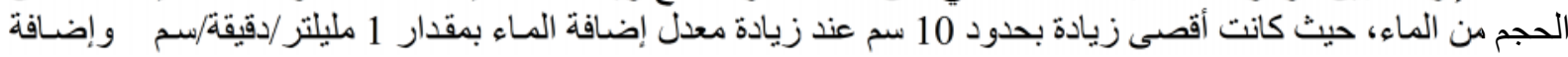
1000مليلتر/سم.

الإز احة بين مركز نمط الابتلال السطحي عن المنقط تزداد مـع زيادة معدل إضـافة المـاء وذلك عند زمن معين منذ .3 بداية إضافة الماء.

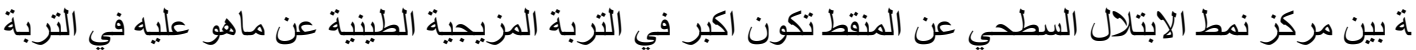
.4

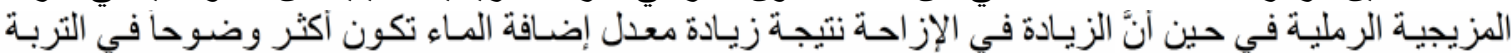
المزيجية الرملية.

5. لايوجد تأثير معنوي لتغير الرطوبة الابتدائية للتربة على الإزاحة بين مركز نمط الابتلال السطحي عن المنقط ولتربتي

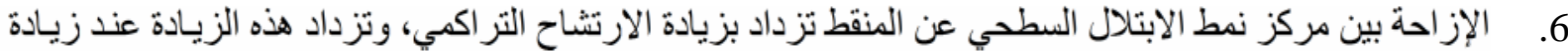

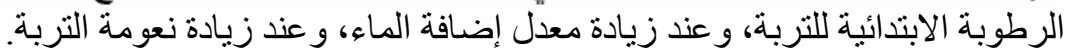

1. Hachum, A.Y. "Water movement in soil from trickle source" M.Sc.Thesis, Utah State University, Logan, Utah, USA (1973).

2. Hammami,M.,H.Daghari, J. Balti, and M.Maalej "Approach for predicting the wetting front depth beneath a surface point source: Theory and numerical aspect" . Irrigation and Drainage (51), 2002 ,pp. 347-360.

3. ياسين، حقي إسماعيل " تأثير الإضافة المتقطعة للماء من مصدر تنقيط على حركة الماء وتوزيع الرطوبة في تربة . (2006)

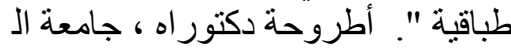

4. Ainechee,G.,S.Boroomand-Nasab and M.Behzad "Simulation of soil wetting pattern under point source trickle irrigation”. Journal of Applied Sciences 9(6), 2009,pp. 1170-1174.

5.محمود، محمد طارق و حقي إسماعيل ياسين، " تقدم جبهة الابتلال وتوزيع الرطوبة في تربـة مزيجية غرينية تحت

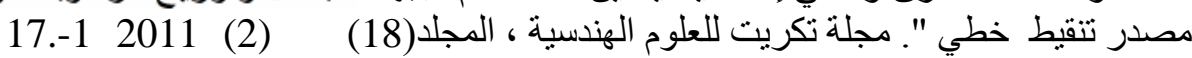

6.حاجم، احمد يوسف و ياسين، حقي إسماعيل " هندسة نظم الري الحقلي" دار الكتب للطباعة و النشر، جامعة الموصل، .(1992) . 
7.Merkley and Allen "Sprinkle and Trickle Irrigation Lectures ". Journal ,ASAE Transactions, International Committee on Irrigation and Drainage(ICID) Journal,and others.Utah stat University,Logan,Utah, (2007) Page 244.

8. Farhad Mirzaei and R.S.Sharif Nia "Model of the soil wetting shape under drip irrigation on sloping lands by using dimensional analysis technique" http:// irncid.org / Get File Articles .aspx ?Fileprm =4821-75032.pdf. 2008.

9. Mohammadi Adel, BigloueiM. Hassan, Khaledian M.Reza,Moridnejad A.Reza and Yazdekhasti Morteza "Wetting pattern inspection on steep lands of fath-ali plain in Moqan" ICID $21^{s t}$ International congress on Irrigation and Draing ,Iran, 2011.

10. Behrouz Mostafazadeh, Sayed -Frahad Mosuavi and Mohammad Hossain SharifBayanolhagh "Wetting front advance from a point source in sloping fields "Iranian Journal of Irrigation and Drainage 2(3) (1998) :pp.13-23.

تم اجراء البحث في كلية ألهنسة = جامعة ألموصل 